BMJ Open Sport \& Exercise Medicine

\title{
Comparison of branded rugby headguards on their effectiveness in reducing impact on the head
}

\author{
Erin R A Frizzell, Graham P Arnold, Weijie Wang, Rami J Abboud, Tim S Drew
}

To cite: Frizzell ERA, Arnold GP, Wang W, et al. Comparison of branded rugby headguards on their effectiveness in reducing impact on the head. BMJ Open Sport \& Exercise Medicine 2018:4:e000361. doi:10.1136/ bmjsem-2018-000361

Accepted 3 0ctober 2018

\section{ABSTRACT}

Aim To compare the available brands of rugby headguards and evaluate their impact attenuation properties at various locations on the cranium, with regard to concussion prevention.

Methods Seven different branded headguards were fitted onto a rigid headform and drop-tested in three different positions. An accelerometer measured the linear acceleration the headform experienced on impact with the ground. Each test involved dropping the headform from a height that generated $103.8 \mathrm{~g}$ on average when bare, which is the closest acceleration to the upper limit of the concussion threshold of $100 \mathrm{~g}$. A mean peak acceleration for each drop position was calculated and compared with the bare baseline measurement.

Results Each headguard demonstrated a significant decrease in the mean peak acceleration from the baseline value (all $p \leq 0.01$ ). Overall the Canterbury Ventilator was the most effective headguard, decreasing the impact force on average by $47 \%$. The least effective was the XBlades Elite headguard, averaging a force reduction of $27 \%$. In five of the seven headguards, the right side of the headwear was the most effective at reducing impact force.

Conclusion Overall, the results indicate that it would be beneficial to wear a headguard during rugby in order to reduce the impact forces involved in head collisions. There was also a clear difference in performance between the tested brands, establishing the Canterbury headguard as the most effective. However, only one model of headguard from each brand was tested, so further research evaluating all other models should be considered.

\section{INTRODUCTION}

(c) Author(s) (or their employer(s)) 2018. Re-use permitted under CC BY-NC. No commercial re-use. See rights and permissions. Published by BMJ.

Institute of Motion Analysis Research (IMAR), Department of Orthopaedic and Trauma Surgery, TORT Centre, Ninewells Hospital \& Medical School, University of Dundee, Dundee, Scotland

Correspondence to Professor Rami J Abboud; r.j. abboud@dundee.ac.uk
Rugby union (hereafter referred to as rugby) has one of the highest incidences of concussion in sport, and rates are continuing to rise. ${ }^{1}$ The latest Injury Surveillance Project (2017) stated that for the sixth consecutive season the occurrence of match concussions within English rugby had increased, reaching a figure of 15.8 concussions per 1000 player-hours. ${ }^{2}$ Since rugby became a professional sport in 1995, full-time training has allowed players to increase their strength, power and fitness, as well as their body mass. This increased physicality is thought to be the cause of the rise in concussion figures. ${ }^{1}$ However, it
Summary box

All headguards reduced the linear acceleration experienced on impact.

- The Canterbury Ventilator was the most effective, while the XBlades Elite was the least effective.

- The headguards used may not prevent all concussive injuries, but there is the potential for them to reduce the incidence.

has been argued that the dramatic increase could be a result of improved awareness of the condition, reflecting previous underdiagnoses rather than a real rise in incidence. ${ }^{3}$ Regardless of the cause of this trend, steps need to be taken to protect players from head impact injury.

In addition to the immediate dangers posed by concussion, research into longterm sequelae of concussion is proposing a link between recurrent head collisions in contact sports and fatal conditions such as second impact syndrome $e^{4-8}$ and chronic traumatic encephalopathy (CTE) ${ }^{9-11}$ The debate surrounding the long-term sequelae of concussion in contact sport is becoming a mainstream issue, with CTE even making it to Hollywood with the film, Concussion. ${ }^{12}$ However, research into both conditions is in its early stages, and some have disputed their existence due to a limited case number. ${ }^{13-15}$

It is estimated that between 1.6 million and 3.8 million sports-related concussions occur each year, but this figure may be an underestimate due to the large number that goes unrecognised and unreported. ${ }^{16}$ Raised awareness of sports-related concussion has sparked a wave of research into the field, primarily in the USA within the American football setting. However, in most contact sports, such as American football, ice hockey and cycling, players use hard-shelled helmets during play, which differ dramatically from the foam-padded headguards used in rugby. While the American studies may not be a useful comparison for headgear, there were 
some studies that attempted to determine a threshold force for concussion, which are useful for evaluating the effectiveness of rugby headgear. ${ }^{17-21}$ Studies within the field of rugby have investigated the epidemiology of head impacts and concussive injuries, such as King et $a l^{17}$ and Gardner et al. ${ }^{1}$ Focusing more on rugby headguards, most of the limited on-pitch testing of headguards has revealed no change in concussion incidence, ${ }^{22-24}$ with the exception of Hollis et al, who demonstrated a decreased frequency of concussion in those who chose to wear a headguard.$^{25}$ Despite this, one of the studies that demonstrated no change in the frequency of concussion while wearing a headguard did highlight a decrease in severity of concussive symptoms in those wearing a headguard. ${ }^{22}$ Taking this further, a laboratory study highlighted that small alterations to the headguards' design could significantly improve their impact attenuation performance. ${ }^{26}$

In response to growing pressures, World Rugby have made reducing the incidence of concussion one of their main priorities. They have focused on education, creating many online resources providing information on recognising and managing concussion within the game of rugby. ${ }^{27}$ They have also changed the laws of the game to punish reckless head collisions. ${ }^{28}$ However, one area World Rugby have not used to prevent concussion is protective headgear. Their laws enforce tight limits on the thickness and density of the material used, ${ }^{29}$ emphasising their purpose is to prevent superficial head injuries which they have proven to do. ${ }^{24}{ }^{30}$ World Rugby argue that wearing headgear would give players a 'false sense of security' and encourage 'risk taking behaviour', resulting in an increase rather than a decrease in head injuries. ${ }^{31}{ }^{32}$ However, research into the effectiveness of headguards has shown the tackle style and frequency do not change when comparing players wearing a headguard with those who are not. ${ }^{23}$

The primary aim of this research was to investigate the efficiency of several branded rugby headguards at reducing the forces transferred to the head on impact. Headguards are the only form of head protection available to rugby players, and there is limited research comparing the efficiency of different brands which are approved by World Rugby. It was hoped the results would point towards a brand of headguard that provided the best protection for players.

\section{METHODS}

\section{Selection of branded headguards}

Three UK-based online rugby stockists (Rugby Store, ${ }^{33}$ Lovell Rugby ${ }^{34}$ and Pro:Direct ${ }^{35}$ ) were searched to identify the brands producing a rugby headguard available to players in the UK. From these searches seven different brands were identified: Adidas, Canterbury, Gilbert, Impact, Kooga, Optimum and XBlades. Some of these brands produced more than one model of headguard; where that was the case, the mid-range (price) design was chosen. The seven headguards selected for testing are shown in figure 1 .

\section{Composition of the test rig}

To evaluate the headguards, a drop test mechanism was designed. This involved a test rig which was developed and constructed in the Tayside Orthopaedic and Rehabilitation Technology Services Centre. It was constructed by attaching a polyvinyl chloride tube via a pivot mechanism onto a wooden base to create a swinging arm. A resin headform built to EN960 specification was screwed into the non-pivoted end of the piping of the test rig. It was chosen due to the negligible fatigue effects of its solid structure. The dimensions of the testing rig are shown in figure $2^{36}$ for completeness. Attached to the top of the headform was a uniaxial accelerometer which recorded the linear acceleration during each test drop, as the testing rig movement was constrained to one plane. The targeted drop height was a height that would generate a force as close to $100 \mathrm{~g}$ as possible, as this figure is at the upper limit of the proposed concussion threshold. ${ }^{17-21}$ The chosen drop height of $27.9 \mathrm{~cm}$ resulted in the headform experiencing $103.8 \mathrm{~g}$ when bare. All drops were carried out onto $4 \mathrm{G}$ artificial surface. This was selected due to the popularity of artificial pitches within rugby, highlighted by almost 30 artificial rugby pitches in existence in Scotland ${ }^{37}$ and the Rugby Football Union's recent campaign to provide 100 of them for the grassroot game across England. ${ }^{38}$

\section{Testing the headguards}

Each headguard was placed on the same headform and tested in three different positions: front, back and side. The position of the headguard referred to the surface of the headguard that would experience the impact with the artificial surface during testing. To initiate the impact, the block of wood was triggered causing the headform to fall onto the artificial grass surface. The data output from the accelerometer was sampled at $100 \mathrm{kHz}$ and recorded via the PicoScope 3204 software. This process was carried out 12 times in each of the three positions, producing 60 drops for each headguard. The bare headform was droptested five times to establish a baseline impact force from the chosen drop height.

\section{Analysing the collected data}

The peak acceleration from each drop test carried out was extracted from the accelerometer recording to generate a peak impact force. The results then underwent statistical analysis using the Statistical Package for Social Sciences (SPSS) V.22 software. Initially, a one-sample t-test was carried out to determine whether there was a significant difference between the baseline value and the values generated by each position of each of the headguards. Once this was established, post-hoc analysis of variance testing using Fisher's least significant difference was carried out to compare the different headguards as well as the different surfaces of the headguards. 

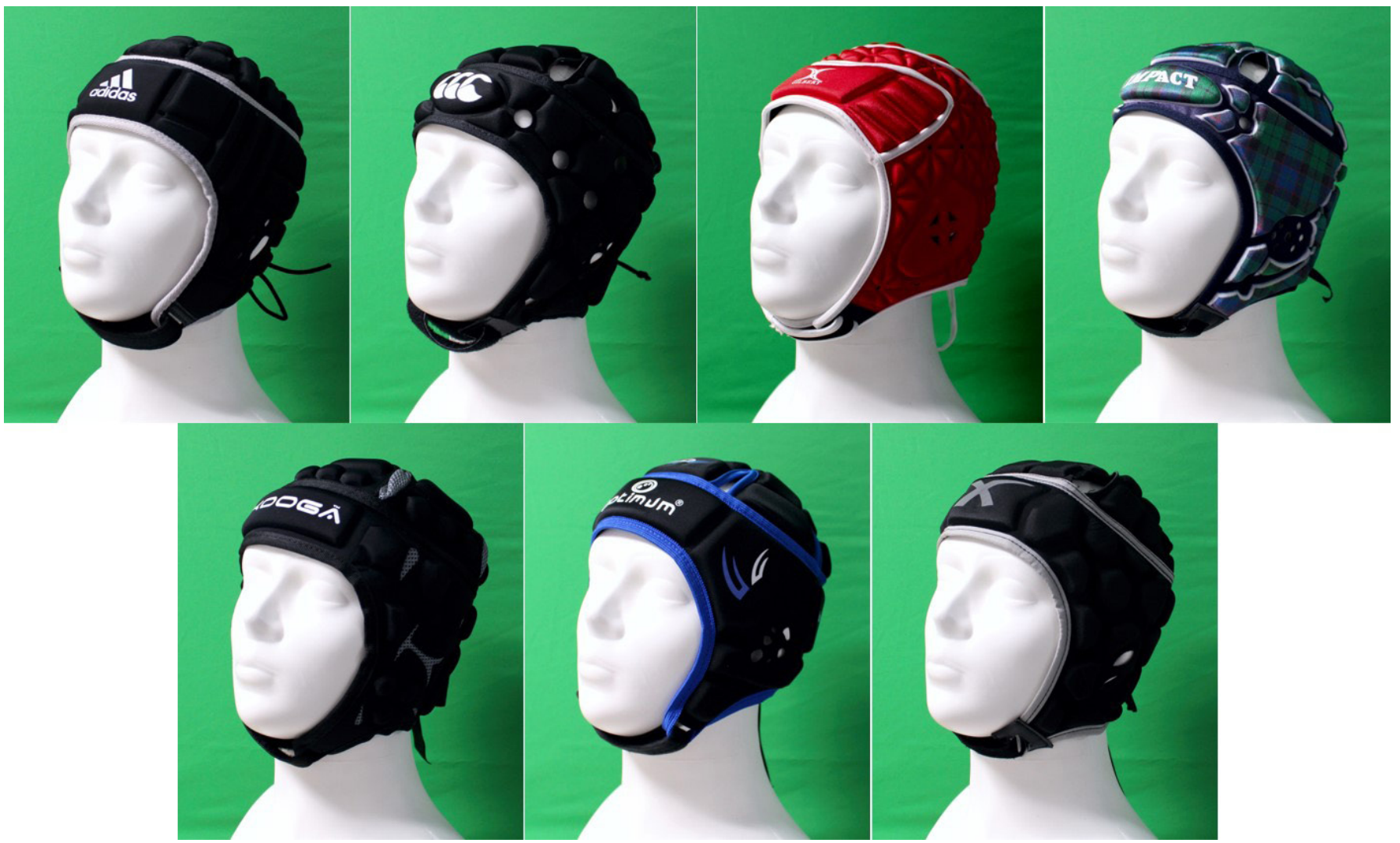

Figure 1 Headguards selected for testing (left to right): Adidas Rugby headguard (£34.95), Canterbury Ventilator headguard (£42.00), Gilbert Evolution headguard (£34.99), Impact RWC Tartan headguard (£39.99), Kooga Combat headguard (£28.99),

Optimum Hedweb Classic headguard (£24.99) and XBlades Elite headguard (£34.99).

\section{RESULTS}

\section{Results by brand}

The mean peak force demonstrated during testing of each brand of headguard is shown in table 1, along with the maximum, minimum, SD and average reduction values. The mean peak acceleration gives a picture of each headguard's overall impact attenuation properties by combining the tests in all positions. A statistically significant reduction $(\mathrm{p}<0.001)$ in linear acceleration was seen in all seven headguards when compared with baseline. The most effective headguard was the Canterbury
Ventilator, which on average produced a $46.7 \%$ reduction in impact force, and the least effective was the XBlades Elite headguard, which produced a $27.4 \%$ reduction.

\section{Results by position}

Table 2 shows the peak acceleration results by position. In comparison with the other two surfaces, the back of the headguards produced less of a reduction in the impact forces $(36 \%)$. There was not much variation between the other two positions, but the front produced the lowest

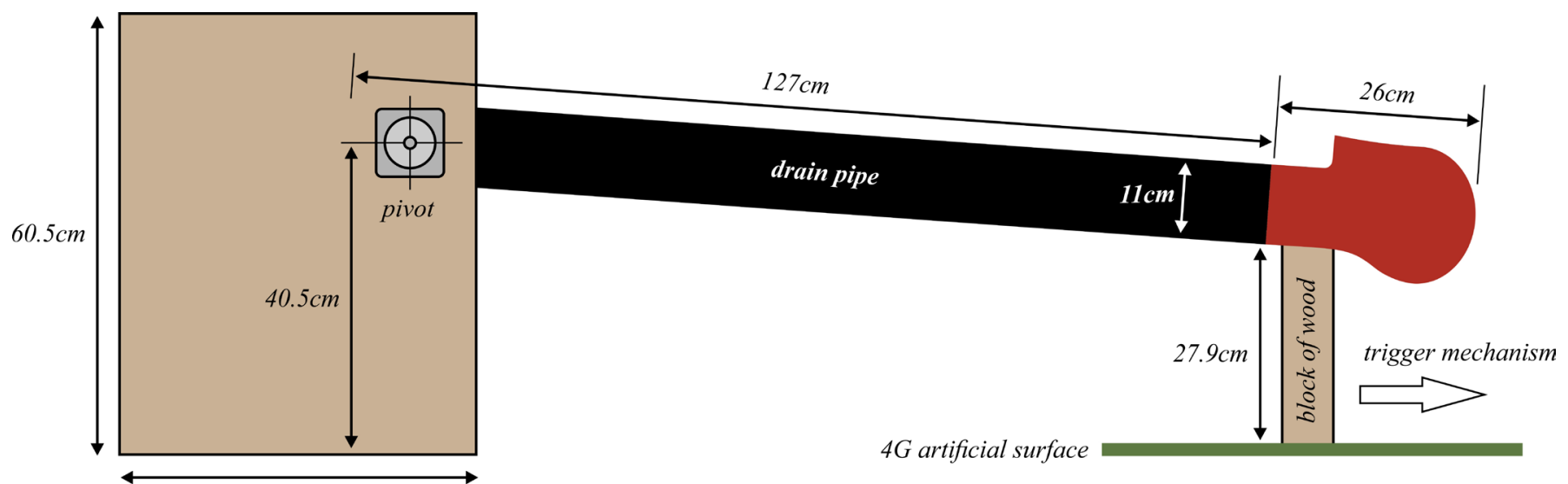

$49.5 \mathrm{~cm}$

Figure 2 Dimensions of the test rig used in the drop testing of the headguards. ${ }^{17}$ 
Table 1 Mean peak acceleration (g) recorded during headguard testing by brand

\begin{tabular}{lllllll}
\hline Brand & Test drops (n) & Mean (g) & Minimum (g) & Maximum (g) & SD & $\begin{array}{l}\text { Average reduction } \\
\text { from baseline (\%) }\end{array}$ \\
\hline $\begin{array}{l}\text { Baseline } \\
\begin{array}{l}\text { Canterbury } \\
\text { Ventilator }\end{array}\end{array}$ & 5 & 103.80 & 98.48 & 106.08 & 3.03 & - \\
$\begin{array}{l}\text { Impact RWC Tartan } \\
\text { Optimum Hedweb }\end{array}$ & 36 & 55.31 & 40.40 & 70.08 & 6.74 & 46.7 \\
$\begin{array}{l}\text { Classic } \\
\text { Adidas Rugby }\end{array}$ & 36 & 59.42 & 45.84 & 80.41 & 8.56 & 42.8 \\
Kooga Combat & 36 & 60.11 & 43.20 & 72.88 & 7.79 & 42.1 \\
Gilbert Evolution & 36 & 60.22 & 41.60 & 80.73 & 9.37 & 42.0 \\
XBlades Elite & 36 & 60.71 & 43.28 & 80.01 & 6.61 & 41.5 \\
\hline
\end{tabular}

mean peak acceleration during testing, reducing linear acceleration by $40 \%$.

\section{Further breakdown of results}

Figure 3 allows comparison of the efficiency of the different branded headguards at each of the three surfaces tested. The highest mean peak acceleration was seen when the XBlades Elite headguard was tested on the right surface, which averaged $81.12 \mathrm{~g}$, while the lowest was obtained from testing the right side of the Canterbury Ventilator headguard, which averaged $52.80 \mathrm{~g}$. Overall, the Canterbury and Impact headguards tended to be the most efficient at the different surfaces, while the least efficient was always either the Gilbert or XBlades headguard.

\section{DISCUSSION}

\section{Comparison of the different branded headguards}

The aim of this research was to evaluate and compare the efficiency of various branded rugby headguards at reducing the forces transferred to the head on impact. All the headguards involved in testing demonstrated a decrease in linear acceleration experienced during impact when compared with the bare headform (all $\mathrm{p}<0.01)$. There was also variation between the headguards, with post-hoc analysis demonstrating that for each of the three positions the most effective headguard was significantly different from the least effective headguard (all $\mathrm{p} \leq 0.001$ ).

This study established the Canterbury Ventilator headguard as the most effective headguard at reducing linear acceleration during collisions to the head. It produced the largest overall reduction of the impact force $(46.7 \%)$ and was consistently in the most efficient half when comparing the headguards in each drop position. It generated the largest mean reduction in acceleration in two of the three positions: the right (49\%) and back $(47 \%)$.

The XBlades Elite headguard was consistently poorer at reducing the impact transferred to the headform compared with the other headguards. Its overall mean peak acceleration was only $27.4 \%$ lower than the baseline and was $20 \mathrm{~g}$ higher than the best performing Canterbury Ventilator headguard. The XBlades Elite headguard also produced the highest peak acceleration values at two of the three positions (right and front). The poorest performing headguard when testing the back position was the Gilbert Evolution headguard, which was also the second most ineffective overall.

\section{Comparison of the different surfaces of the headguards}

Different locations on the headguards were tested to determine the best protected parts of the cranium during a collision. Looking at the results from the three positions tested, the highest mean result was the back with $66.24 \mathrm{~g}$, while the lowest was the front with $61.22 \mathrm{~g}$. The slightly higher mean result for the back of the headguards when compared with the front and side is most likely due to the headwear design. The back region of the headguards features the tightening mechanism so as a result has less foam padding, reducing the headguards' impact attenuation properties in this area.

Table 2 Mean peak acceleration (g) recorded during headguard testing by position

\begin{tabular}{lllllll}
\hline Position & Test drops (n) & Mean $(\mathbf{g})$ & Minimum $\mathbf{( g )}$ & Maximum $\mathbf{( g )}$ & SD & \multicolumn{1}{c}{$\begin{array}{l}\text { Average reduction } \\
\text { from baseline (\%) }\end{array}$} \\
\hline Baseline & 5 & 103.80 & 98.48 & 106.08 & 3.03 & - \\
Front & 84 & 61.22 & 40.80 & 81.77 & 9.41 & 41.0 \\
Right & 84 & 62.32 & 40.40 & 91.53 & 13.41 & 40.0 \\
Back & 84 & 66.24 & 43.04 & 84.57 & 8.92 & 36.2 \\
\hline
\end{tabular}




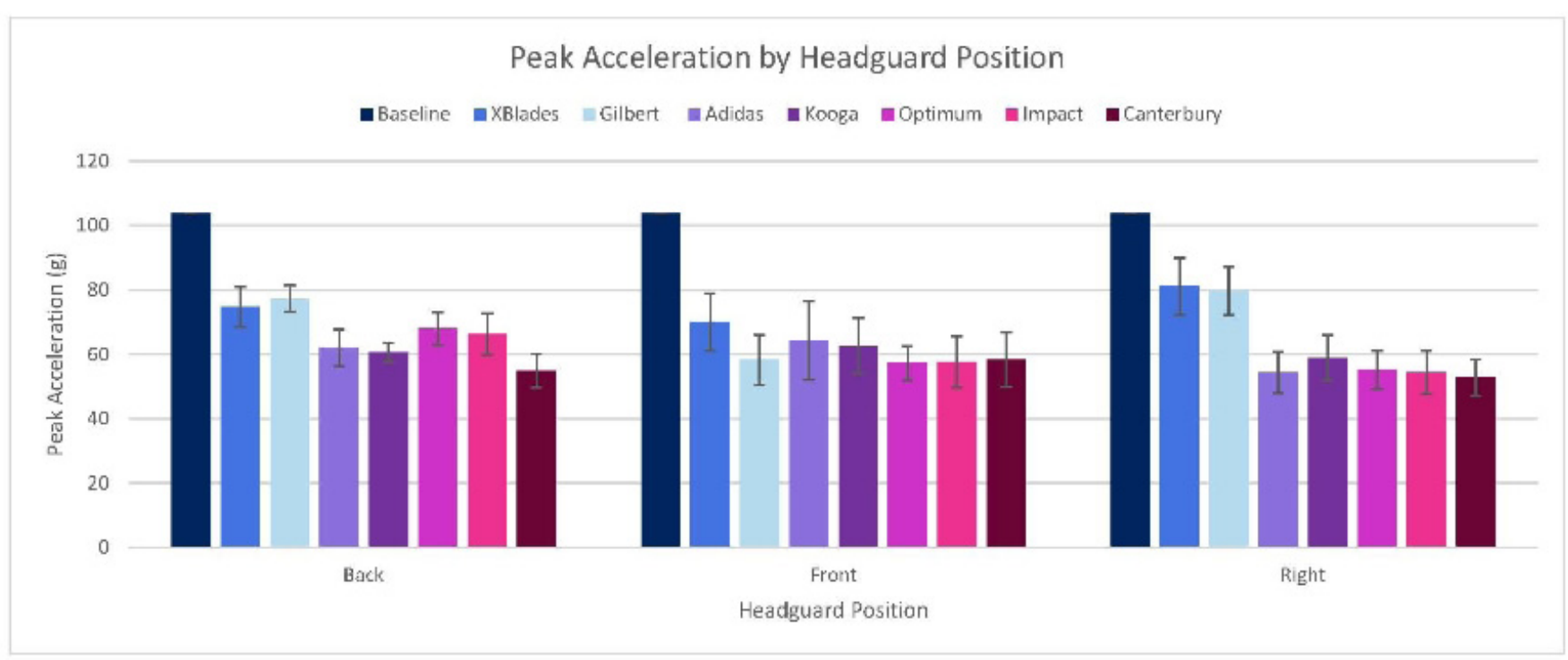

Figure 3 Mean peak acceleration (g) recorded in each headguard position.

When analysing the test drops on the front of the headwear, there is not much variation between the different brands. The post-hoc analysis showed no significant difference between the headguards when dropped on the front, with one exception: the XBlades Elite. The results from the front testing of this headguard were significantly different from almost all the other headguards. The narrow range in the results on front testing is most likely due to the similarity in the design of the headwear. Each headguard has an oblong-shaped foam block on the forehead aspect of the headgear. Therefore, any difference in the results between drops on the front is more likely due to the material compositions of the headguards rather than the design implemented.

Only one side of the headguards was tested as all seven headguards had a symmetrical design. The right side was chosen as previous research has shown the right side of the head to be the most common site for head collisions during rugby match play. ${ }^{17}$ There was a large range in effectiveness between the headguards when testing their right side; both the highest and lowest mean peak acceleration produced resulted from testing on the right side. The Canterbury Ventilator averaged $52.80 \mathrm{~g}$ when dropped, while the XBlades averaged almost $30 \mathrm{~g}$ higher at $81.12 \mathrm{~g}$; these results made the right side the Canterbury headguard's strongest site, while it was the XBlades' weakest.

Potential for the headguard to reduce incidence of concussion One of the main objectives of this research was to determine if the headguards available to players have the potential to reduce the incidence of concussion in rugby. When comparing the overall mean peak acceleration values for each headguard generated in this research against the $80-100 \mathrm{~g}$ concussion threshold proposed by current research, ${ }^{17-21}$ there is strong evidence that headguards may reduce the incidence of concussion. This is demonstrated by each headguard producing a mean peak acceleration lower than the $80 \mathrm{~g}$ value. However, analysis of the individual drop test results suggests concussion may not always be prevented by headguard use. While the Canterbury, Impact and Optimum headguards did not produce a single drop test which exceeded the suggested $80 \mathrm{~g}$ threshold value, the other headguards did. Although the Kooga and Adidas headguards only saw one drop test go over $80 \mathrm{~g}$, the Gilbert and XBlades headguards had a much larger figure: 19\% of the Gilbert test drops and $31 \%$ of the XBlades test drops exceeded $80 \mathrm{~g}$. Furthermore, when the XBlades Elite headguard was tested on the right side, two-thirds of the results surpassed $80 \mathrm{~g}$.

However, as has been previously acknowledged, the threshold for concussion is still widely debated, and accepting a specific value must be done with caution. Furthermore, research has demonstrated incidents of concussion occurring from forces as small as $54.9 \mathrm{~g},{ }^{17}$ which is lower than the overall mean peak acceleration generated by each of the headguards tested in this study. Additionally, there are other variables which will influence whether an impact during play will result in concussion. These include cerebrospinal fluid levels and musculoskeletal strength, which can influence the body's ability to disperse head impact forces. ${ }^{21}$ While these factors are important to consider, in reducing the forces involved in collisions, it seems rational to suggest that this could lead to decreased concussion rates.

\section{Limitations}

This study relied on lab testing: prior research in this field indicates positive testing of headguards in the lab does not always translate into reduction in concussion rates on the rugby field. ${ }^{39}$ The testing rig was set up to simulate 
head collisions with the ground. However, prior research has demonstrated that $53 \%$ of concussive injuries that occur during rugby matches result from tackling. ${ }^{40}$ Therefore, further research into the biomechanics involved in this kind of head impact may provide a more accurate way of evaluating the headguards. Data collection also only involved linear acceleration measurements despite research pointing towards angular acceleration playing an important role in concussive injuries. However, in a recent study, data from drop testing within a laboratory setting were compared with data from real-life American football head collisions, and it found that angular acceleration values from the laboratory were $46 \%$ lower when compared with pitch impacts. ${ }^{41}$ Drop testing is therefore not an accurate way to simulate and assess the angular component of concussive impacts and so only linear measurements were collected during this study.

\section{Recommendations for future research}

Recommendations in this area primarily involve wider testing of the headguards. Only one model from each brand was selected for testing, but it may be beneficial to investigate if other models from the tested brands demonstrate the same pattern in efficiency. There was also a slight decline in impact attenuation over serial drops with the same headguard, although this was attributed to the compression of the grass surface with repeated impact and therefore losing some of its cushioning effect. Further analysis of the performance deficit of the headgear over time could therefore be considered. It may also be worth carrying the research forward into live testing to identify if there is a difference in concussion incidence while wearing different branded headguards.

\section{CONCLUSION}

All headguards included in this study were shown to decrease the linear acceleration forces experienced during impact but with varying efficiency. The most effective brand was Canterbury. While the mean peak acceleration for each headguard was lower than the proposed injury threshold, there were individual drop tests which surpassed it. This suggests that while the headguards may not always be effective at preventing concussion, they may be effective at reducing the incidence of the injury. Until World Rugby make effective headguard development a priority, this research demonstrates current headguards are worth considering as they do decrease linear acceleration experienced on impact.

Acknowledgements The authors would like to acknowledge lan Christie and Callum Macdonald for their valuable contribution and advice.

Contributors All coauthors are in agreement to be accountable for all aspects of the work presented in this manuscript. ERAF: planning the study, conducting the study, analysing the data, reporting the study, generating the write-up, responsible for the overall content as guarantor. GPA: coplanning the study, analysing the data. WW: statistical analysis of data, revising the manuscript. RJA: reporting the study, revising the original and revision manuscript critically for intellectual content, submitting the study, responsible for the overall content as guarantor. TSD: coplanning the study, design of the testing apparatus, analysing the data.
Funding This study was internally funded by the department. No external funding was received.

Competing interests None declared.

Patient consent Not required.

Provenance and peer review Not commissioned; externally peer reviewed.

Open access This is an open access article distributed in accordance with the Creative Commons Attribution Non Commercial (CC BY-NC 4.0) license, which permits others to distribute, remix, adapt, build upon this work non-commercially, and license their derivative works on different terms, provided the original work is properly cited, appropriate credit is given, any changes made indicated, and the use is non-commercial. See: http://creativecommons.org/licenses/by-nc/4.0/.

\section{REFERENCES}

1. Gardner AJ, Iverson GL, Williams WH, et al. A systematic review and meta-analysis of concussion in rugby union. Sports Med 2014:44:1717-31.

2. England Professional Rugby Injury Surveillance Project Steering Group. England Professional Rugby Injury Surveillance Project 20152016 Season Report, 2017.

3. Schofield D. Rugby concussions soar by 59 per cent, says report, 2015. Available from: https://www.telegraph.co.uk/sport/rugbyunion/ premiership/11407436/Rugby-concussions-soar-by-59-per-centsays-report.html [Accessed 20 Jun 2018].

4. Cantu RC, Voy R. Second impact syndrome: a risk in any contact sport. The Physician and Sportsmedicine 1995;22:27-34.

5. Bey T, Ostick B, Syndrome SI. Second impact syndrome. West J Emerg Med 2009;10:6-10.

6. Mueller FO. Catastrophic head injuries in high school and collegiate sports. J Ath/ Train 2001;36:312-5.

7. McCrory P. Does second impact syndrome exist? Clin J Sport Med 2001;11:144-9.

8. McLendon LA, Kralik SF, Grayson PA, et al. The controversial second impact syndrome: a review of the literature. Pediatr Neurol 2016;62:9-17.

9. Omalu BI, DeKosky ST, Minster RL, et al. Chronic traumatic encephalopathy in a national football league player. Neurosurgery 2005;57:128-34

10. Harmon KG, Drezner JA, Gammons M, et al. American medical society for sports medicine position statement: concussion in sport. Br J Sports Med 2013;47:15-26.

11. Baugh CM, Stamm JM, Riley DO, et al. Chronic traumatic encephalopathy: neurodegeneration following repetitive concussive and subconcussive brain trauma. Brain Imaging Behav 2012;6:244-54.

12. Concussion. Film] Directed by Peter Landesman. United States of America: The Cantillon Company, LStar Capital, Scott Free Productions, The Shuman Company, Village Roadshow Pictures 2015.

13. McCrory P, Davis G, Makdissi M. Second impact syndrome or cerebral swelling after sporting head injury. Curr Sports Med Rep 2012;11:21-3.

14. Hebert $O$, Schlueter K, Hornsby M, et al. The diagnostic credibility of second impact syndrome: A systematic literature review. J Sci Med Sport 2016;19:789-94.

15. Maroon JC, Winkelman R, Bost J, et al. Chronic traumatic encephalopathy in contact sports: a systematic review of all reported pathological cases. PLoS One 2015;10:e0117338.

16. Langlois JA, Rutland-Brown W, Wald MM. The epidemiology and impact of traumatic brain injury: a brief overview. J Head Trauma Rehabil 2006;21:375-8.

17. King D, Hume PA, Brughelli M, et al. Instrumented mouthguard acceleration analyses for head impacts in amateur rugby union players over a season of matches. Am J Sports Med 2015;43:614-24

18. Brolinson PG, Manoogian S, McNeely D, et al. Analysis of linear head accelerations from collegiate football impacts. Curr Sports Med Rep 2006:5:23-8.

19. Guskiewicz KM, Mihalik JP. Biomechanics of sport concussion: quest for the elusive injury threshold. Exerc Sport Sci Rev 2011;39:4-11.

20. Pellman EJ, Viano DC, Tucker AM, et al. Concussion in professional football: reconstruction of game impacts and injuries. Neurosurgery 2003:53:799-814.

21. Mihalik JP, Bell DR, Marshall SW, et al. Measurement of head impacts in collegiate football players: an investigation of positional and event-type differences. Neurosurgery 2007;61:1229-35. 
22. McIntosh AS, McCrory P, Finch CF, et al. Does padded headgear prevent head injury in rugby union football? Med Sci Sports Exerc 2009;41:306-13.

23. McIntosh AS, McCrory P. Effectiveness of headgear in a pilot study of under 15 rugby union football. Br J Sports Med 2001;35:167-9.

24. Marshall SW, Loomis DP, Waller AE, et al. Evaluation of protective equipment for prevention of injuries in rugby union. Int $\mathrm{J}$ Epidemiol 2005;34:113-8.

25. Hollis SJ, Stevenson MR, Mclntosh AS, et al. Incidence, risk, and protective factors of mild traumatic brain injury in a cohort of Australian nonprofessional male rugby players. Am J Sports Med 2009;37:2328-33.

26. Eager D, Chapman C, Suwidji K. Is current rugby headgear adequate? 8th Australasian Congress on Applied Mechanics 2014;8:244-51.

27. World Rugby. World Rugby Concussion Management, 2017. Available from: http://playerwelfare.worldrugby.org/concussion [Accessed 25 Apr 2017].

28. Aylwin M. Rugby union's new tackle laws: what are they and will they make a difference, 2017. Available from: https://www.theguardian. com/sport/blog/2017/jan/06/world-rugby-new-tackle-laws-what-arethey [Accessed 25 Mar 2017].

29. World Rugby, 2015. Regulation 12. Provisions relating to players dress, 2017. Available from: http://playerwelfare.worldrugby.org/ reg12 [Accessed 28 April 2017].

30. Jones SJ, Lyons RA, Evans R, et al. Effectiveness of rugby headgear in preventing soft tissue injuries to the head: a case-control and video cohort study. Br J Sports Med 2004;38:159-62.

31. Finch CF, McIntosh AS, McCrory P. What do under 15 year old schoolboy rugby union players think about protective headgear? $\mathrm{Br}$ J Sports Med 2001;35:89-94.

32. Pettersen JA. Does rugby headgear prevent concussion? Attitudes of Canadian players and coaches. Br J Sports Med 2002;36:19-22.
33. Rugby Store. Rugby Store: Rugby Headguards, 2016. Available from: http://www.rugbystore.co.uk/equipment/protective/ headguards [Accessed 20 Nov 2016].

34. Lovell Rugby. Lovell Rugby: Rugby Head Guards, 2016. Available from: https://www.lovell-rugby.co.uk/shop/Group/Protection/Type/ Head-Guards [Accessed 20 Nov 2016].

35. Pro:Direct. Pro:Direct: Rugby Head Guards, 2016. Available from: http://www.prodirectrugby.com/lists/rugby-protection-head-guards. aspx [Accessed 20 Nov 2016]

36. Christie IS. Experimentation_rig.jpg [custom image] @ Department of Orthopaedic and Trauma Surgery, University of Dundee 2017.

37. Scottish Rugby Union. Conditional Approvals Granted for Artificial Turf Surfaces for Rugby Union, 2015. RU Listed artificial pitches. Available from: http://www.scottishrugby.org/sites/default/files/ editor/images/schedule_of_approved_artificial_surfaces_world_ rugby_reg_22_-_09_11_1.pdf [Accessed 20 Jun 2018].

38. Rugby Football Union. 100 new artificial pitches for grassroots rugby, 2015. Available from: http://www.englandrugby.com/news/ rfu-fund-100-new-artificial-pitches-for-grassroots-rugby/ [Accessed 18 Jun 2018]

39. McCrory P, Meeuwisse WH, Aubry M. Consensus statement on concussion in sport: the 4th International Conference on Concussion in Sport held in Zurich. British Journal of Sports Medicine 2012;2013:250-8.

40. Cross M, Kemp S, Smith A, et al. Professional Rugby Union players have a $60 \%$ greater risk of time loss injury after concussion: a 2-season prospective study of clinical outcomes. Br J Sports Med 2016:50:1-6.

41. Hernandez F, Shull PB, Camarillo DB. Evaluation of a laboratory model of human head impact biomechanics. J Biomech 2015;48:3469-77. 